Check for updates

Cite this: RSC Adv., 2019, 9, 14859

Received 1st February 2019

Accepted 30th April 2019

DOI: $10.1039 / c 9 r a 00869 a$

rsc.li/rsc-advances

\section{Enhanced electrochemical properties of cellular CoPS CC nanocomposites for HER, OER and Li-ion batteries $\uparrow$}

\begin{abstract}
Miao Wang and Kaibin Tang (D) *
Cellular COPSAC nanocomposites were successfully synthesized via a facile two-steps route. The performances of the CoPSAC electrode as a non-noble metal electrocatalyst for hydrogen evolution reaction (HER) and oxygen evolution reaction (OER) show good activity. On the other hand, the electrochemical investigation of CoPS systems for lithium ion batteries (LIBs) is reported for the first time. The CoPS $\mathrm{CC}$ nanocomposite as a novel anode can maintain a capacity of about $713 \mathrm{~mA} \mathrm{~h} \mathrm{~g}^{-1}$ after 50 cycles at a current density of $0.2 \mathrm{~A} \mathrm{~g}^{-1}$, indicating its potential applications in lithium storage. Test results also demonstrate that the COPS@C nanocomposite exhibit more excellent HER, OER and Li storage performances compared to the bulk CoPS sample.
\end{abstract}

\section{Introduction}

Due to the rapidly increasing demand for energy and extensive use of fossil fuels, there is an urgent need to find alternative sources of clean energy to solve the growing environmental problems. In this regard, hydrogen, as the most abundant element in the universe, has a high energy density and is ecofriendly. ${ }^{1-5}$ Among various methods, the water electrolysis reaction $\left(\mathrm{H}_{2} \mathrm{O} \rightarrow \mathrm{H}_{2}+1 / 2 \mathrm{O}_{2}\right)$, including hydrogen evolution (HER) at the cathode and oxygen evolution (OER) at the anode, is considered as a very promising approach for hydrogen production with high purity. ${ }^{6-10}$ However, the electrocatalytic techniques for water splitting heavily rely on noble metal catalysts such as Pt for the HER and $\mathrm{IrO}_{2} / \mathrm{RuO}_{2}$ for the OER. Thus, it is highly desirable to find earth-abundant, low-cost, and highly active catalysts for water splitting. In order to address these challenges, various classes of electrocatalysts, such as transition-metal phosphides (TMPs) ${ }^{11-18}$ and transition-metal chalcogenides (TMCs) ${ }^{19,20}$ were developed, which were investigated for electrocatalytic application. Some studies have shown that the synergistic effects between TMPs and TMCs can effectively improve the electrochemical performance. ${ }^{21,22}$ Therefore, bifunctional electrocatalytic application ternary transition-metal phosphide-chalcogenides (TMPCs) is a research field with great potential. In particular, the pyrite-type ternary compound cobalt phosphosulfide (CoPS) has recently been demonstrated as a highly efficient

Hefei National Laboratory for Physical Sciences at the Microscale, Department of Chemistry, University of Science and Technology of China, Hefei, 230026, China. E-mail:kbtang@ustc.edu.cn

$\dagger$ Electronic supplementary information (ESI) available. See DOI: 10.1039/c9ra00869a earth-abundant non-noble catalyst for robust electrochemical tests. $^{23-25}$

On the other hand, Li-ion batteries (LIBs) which are considered to be another kind of substitutes of finite fossil fuel, are promising power sources in energy storage devices, portable electronics and electric vehicles. ${ }^{26-30}$ Because of the low theoretical capacity of commercial graphite $\left(372 \mathrm{~mA} \mathrm{~h} \mathrm{~g}^{-1}\right)$ and poor rate performance, ${ }^{31}$ the research of new anode materials with more excellent electrochemical performances is one of the most widely investigated topics in LIBs. ${ }^{32-34}$ As previously reported, cobalt phosphide ${ }^{35-37}$ and cobalt sulfide ${ }^{38-41}$ as anode materials have been widely investigated. However, to the best of our knowledge, the electrochemical investigation of CoPS system as anode for lithium ion batteries (LIBs) have not been reported yet.

In general, the nanostructured materials and coating with carbon are two main approaches which can significantly improve their electrochemical performance. ${ }^{42-45}$ Herein, a cellular CoPS@C nanocomposite was successfully prepared via a facile two-steps route and its electrochemical properties were examined for HER, OER and LIBs. The test results show that it exhibit better electrochemical properties than bulk material.

\section{Experimental section}

\section{Sample synthesis}

In a typical synthesis, powder of cobalt(II) acetylacetonate $(97 \%)$ firstly was loaded into a stainless steel autoclave of $20 \mathrm{~mL}$ capacity, and sealed and heated at $973 \mathrm{~K}$ for $10 \mathrm{~h}$. Then the dark precipitates of Co@C were collected without any purified treatment. Secondly, powders of Co@C, red phosphorus $(99 \%)$ and sublimate sulphur (99\%) were thoroughly 
mixed together, encapsulated in an evacuated quartz tube, and followed by a sintering procedure at $923 \mathrm{~K}$ for $24 \mathrm{~h}$, which is illustrated in Scheme 1. Bulk CoPS sample was also successfully prepared by conventional solid state method. Powders of the elements Co (99.5\%), red phosphorus (99\%) and sublimate sulphur (99\%) were thoroughly mixed together, then sealed into quartz ampoule evacuated. The ampoule was slowly heated up to $923 \mathrm{~K}$, holding for $24 \mathrm{~h}$. After the tube was naturally cooled to room temperature, the product was collected carefully, washed with absolute alcohol several times, and finally dried in a vacuum furnace at $60{ }^{\circ} \mathrm{C}$ for subsequent tests.

\section{Structural characterization}

The phases and purity of the obtained products were characterized by X-ray powder diffraction an a Philips X'pert X-ray diffractometer equipped with $\mathrm{Cu} \mathrm{K} \alpha$ radiation $(\lambda=1.5418 \AA)$. The scanning electron microscopy (SEM) images were taken by using a JEOL-JSM-6700F field-emitting (FE) scanning electron microscope. The high-resolution transmission electron microscope (HRTEM) images were taken on a JEOL2010 HRTEM at an acceleration voltage of $200 \mathrm{kV}$, and the samples for analysis were prepared by dipping carbon coated copper grids into ethanolic solutions of samples and drying under ambient conditions. X-ray photoelectron spectroscopy (XPS) was performed on Thermo ESCALAB 250. Raman spectroscopy is carried out on a JY LABRAM-HR confocal laser micro-Raman spectrometer using $\mathrm{Ar}^{+}$laser excitation with a wavelength of $514.5 \mathrm{~nm}$. The weight percentage of carbon is characterized by elemental analysis (EA, Elemental vario EL cube, Thermal Conductivity Detector) at pure oxygen atmosphere.

\section{Electrochemical characterization}

All the electrochemical measurements were performed with a CHI660E electrochemical workstation (Shanghai Chenhua Instrument Corporation, China) at room temperature. The carbon cloth was firstly washed with acetone, alcohol and water, then dried in a vacuum for subsequent HER and OER tests. The catalysts $(5 \mathrm{mg})$ were dispersed into $1 \mathrm{~mL}$ solution containing $500 \mu \mathrm{L}$ ethanol and $500 \mu \mathrm{L}$ deionized water, then the dispersion was sonicated until a homogeneous black ink was formed. Then $30 \mu \mathrm{L}$ of the slurry was drop-cast onto a carbon cloth $(0.5 \mathrm{~cm} \times 0.5 \mathrm{~cm})$ followed by drying in an oven at $80{ }^{\circ} \mathrm{C}$. The HER and OER activities were evaluated by using a CHI660E electrochemical analyzer (CH Instruments, Inc., Shanghai, China) in a standard three-electrode system, using $\mathrm{Ag} / \mathrm{AgCl}$ (saturated $\mathrm{KCl}$ solution) as the reference electrode, a platinum electrode as the counter electrode and the modified carbon cloth electrode as the working electrode. All the linear sweep voltammetry (LSV) curves were recorded at $5 \mathrm{mV}$ $\mathrm{s}^{-1}$ for the performance test. For comparison, the catalytic activity of commercial $\mathrm{Pt} / \mathrm{C}(20 \mathrm{wt} \%)$ and $\mathrm{RuO}_{2}$ were also tested with the carbon cloth as the substrate and the same mass loading was applied. The cyclic voltammetry (CV) was carried out from 0.36 to $0.46 \mathrm{~V}$ at a scan rate of $2 \mathrm{mV} \mathrm{s}^{-1}, 4 \mathrm{mV} \mathrm{s}^{-1}$, $6 \mathrm{mV} \mathrm{s}^{-1}, 8 \mathrm{mV} \mathrm{s}^{-1}$, and $10 \mathrm{mV} \mathrm{s}^{-1}$. Electrochemical impedance spectroscopy (EIS) was used at frequencies from 100000 to $0.01 \mathrm{~Hz}$ at $0.6 \mathrm{~V}$ for OER. The amperometric $i-t$ curve measurements were tested at $10 \mathrm{~mA} \mathrm{~cm}^{-1}$ current density. All the potentials were calibrated with respect to the reversible hydrogen electrode $(\mathrm{RHE}): E(\mathrm{RHE})=E(\mathrm{Ag} / \mathrm{AgCl})+0.059 \times \mathrm{pH}$ +0.197 .

Coin-type 2016 cells for lithium storage performance test are assembled in an argon-filled glove-box $\left(\mathrm{O}_{2}, \mathrm{H}_{2} \mathrm{O}<1 \mathrm{ppm}\right)$ with lithium foil worked as the anode, celgard 2400 worked as the separator, and 1.0 $\mathrm{M} \mathrm{LiPF}_{6}$ in ethylene carbonate (EC)/ diethyl carbonate (DEC) (1:1 by volume) worked as the electrolyte. The working electrode was prepared by mixing active material, carbon black and polyvinylidene fluoride (PVDF) at a weight ratio of $6: 2: 2$ in $N$-methyl-2-pyrrolidone (NMP). Then the mixture is ball-milling for ten hours to mix uniformly, the obtained slurry was spread on $\mathrm{Cu}$ foil substrate and dried at $80^{\circ} \mathrm{C}$ in a vacuum oven for $10 \mathrm{~h}$. The loading mass of the CoPS@C anode material is around $1 \mathrm{mg}$. Galvanostatic measurements are performed using a LAND-CT2001A instrument in the potential range of $0.01-3 \mathrm{~V}\left(v s . \mathrm{Li} / \mathrm{Li}^{+}\right)$at a designated current density at constant room temperature.

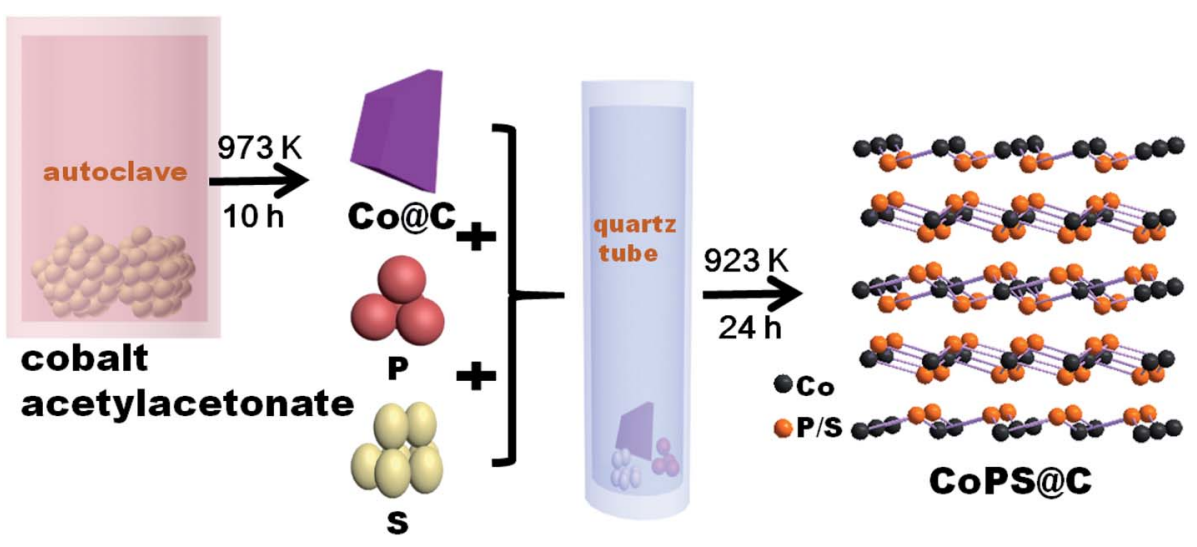

Scheme 1 Schematic illustration of the preparation of CoPS@C. 

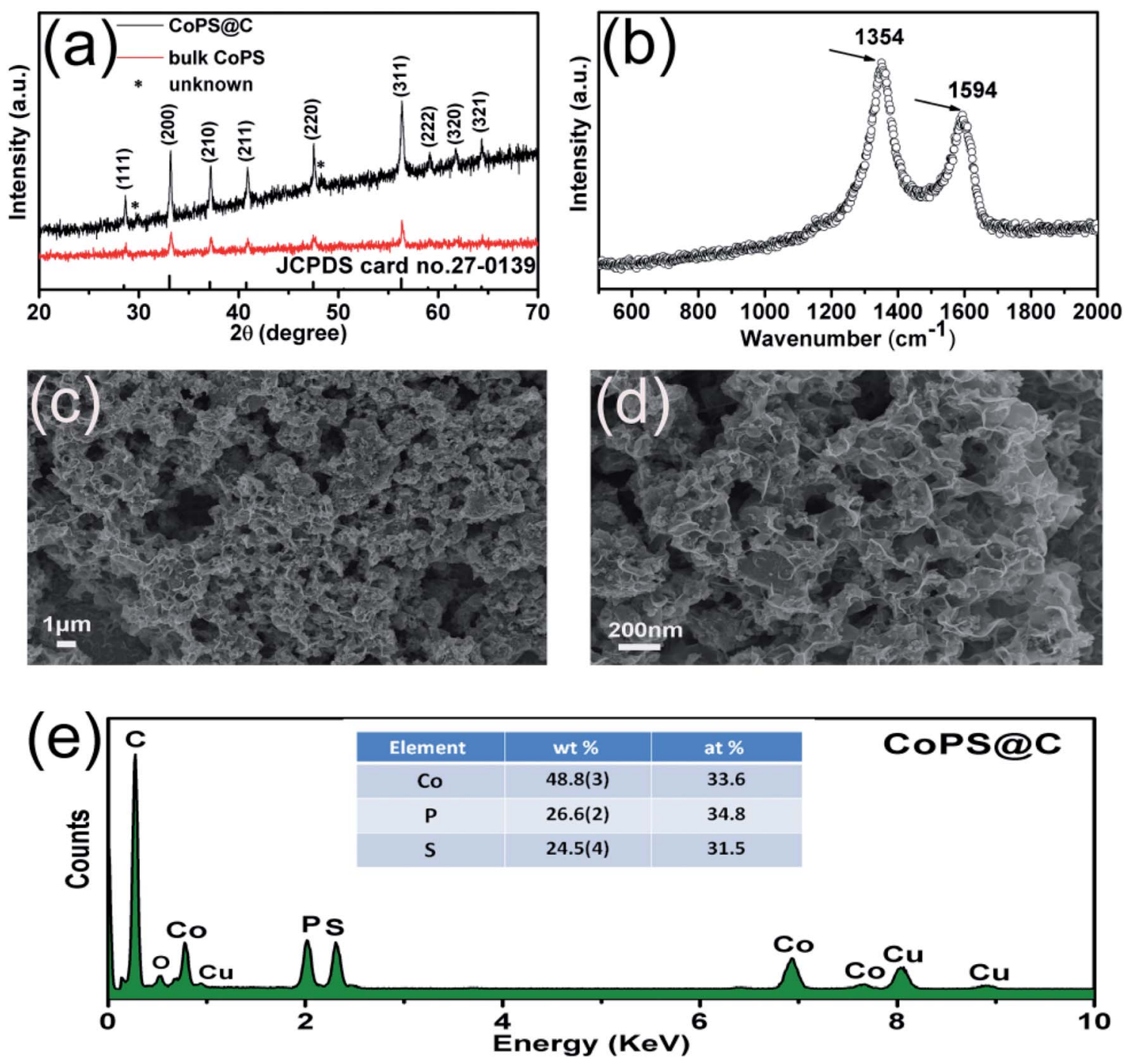

Fig. 1 (a) Powder X-ray diffraction patterns of CoPS@C and bulk CoPS samples. (b) Raman spectrum of the CoPS@C sample. (c) Low-magnified, and (d) high-magnified SEM images of the COPS@C nanocomposite. (e) The EDX spectra for the CoPS@C nanocomposite, and the signal of Cu arises from the TEM grid.

\section{Results and discussion}

CoPS as ternary alloy crystallizes in a typical pyrite compound, as displayed in Scheme 1. The phases of the as-obtained CoPS@C and bulk CoPS samples were analyzed by powder Xray diffraction (XRD), and the results are shown in Fig. 1a. The main diffraction peaks could be well indexed based on a cubic-type cell with the space group of Pa3 (CoPS: JCPDS card no. 27-0139). Fig. 1b shows the Raman spectrum of the sample, two characteristic peaks located at $1354 \mathrm{~cm}^{-1}$ and $1594 \mathrm{~cm}^{-1}$ are detected, which can be attributed to the $\mathrm{D}$ - and G-bands of graphite, respectively. In detail, the D-band is attributed to the vibration of carbon atoms with dandling bonds in plane terminations of disordered graphite, while the G-band is corresponds to an $\mathrm{E}_{2 \mathrm{~g}}$ vibration mode of graphite and is associated with the vibration of carbon $\mathrm{sp}^{2}$ atoms in $2 \mathrm{D}$ hexagonal lattice. The ratio between $I(\mathrm{D}$ band $) / I(\mathrm{G}$ band $)$ is very high, which suggests the presence of a high component of disordered carbon in the samples. ${ }^{46-49}$ Elemental analysis reveals that the carbon content of the CoPS@C nanocomposite is about $14.28 \mathrm{wt} \%$. Fig. 1c and d show representative SEM images of the as-prepared cellular CoPS@C nanocomposite with different magnification. The microstructure of product shows a uniform and typical cellular morphology. The EDX spectra (Fig. 1e) confirms that these composites are composed of $\mathrm{C}, \mathrm{Co}, \mathrm{P}$ and $\mathrm{S}$ elements and the trace oxygen signal may be caused by surface oxidation.

To identify the microstructures of the CoPS@C nanocomposite, high-resolution TEM (HRTEM) images are collected. Fig. 2a reveals that these lumpy structures consist of CoPS nanoparticles and carbon layers; meanwhile, these CoPS nanoparticles are dispersed in the carbon layers without severe agglomeration and the diameter of the nanoparticle is estimated to be $50 \mathrm{~nm}$. Fig. 2c shows the HRTEM image of the CoPS@C nanocomposite, the clear crystal lattice with $d$-spacing 

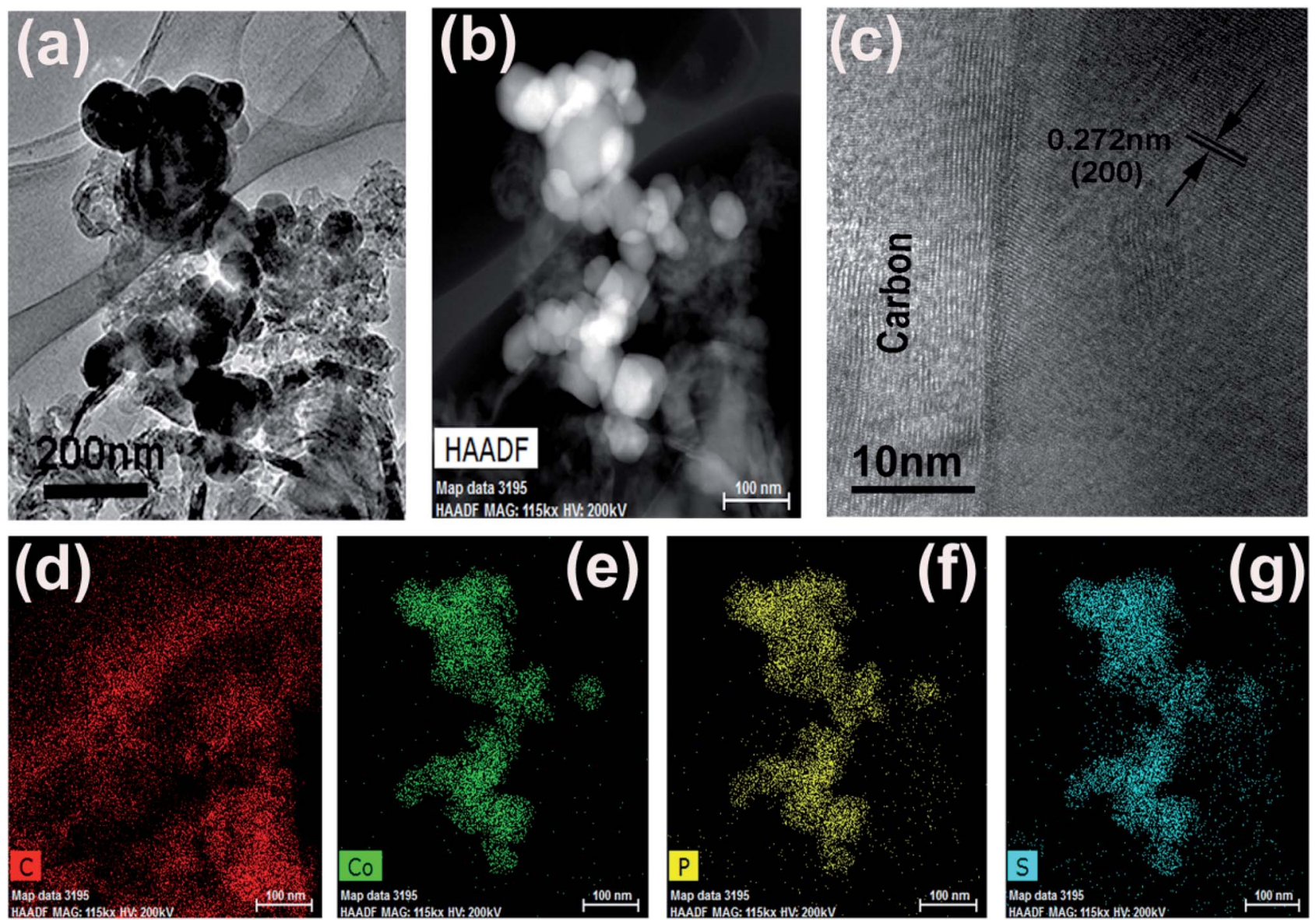

Fig. 2 (a) TEM, (b) HAADF-STEM (c) HRTEM images and ( $d-g)$ the corresponding EDX mapping images of the as-prepared CoPS@C nanocomposite, C (red), Co (green), P (yellow) and S (blue).

of $0.272 \mathrm{~nm}$, which correspond to the (200) plane of CoPS crystal. The HAADF-STEM and corresponding EDX mapping images of the CoPS@C nanocomposite are shown in Fig. $2 \mathrm{~b}$ and $\mathrm{d}-\mathrm{g}$. These images further confirm the homogeneous distributions of cobalt, phosphorus and sulfur elements in the particles, which are encapsulated with carbon layers.

X-ray photoelectron spectroscopy (XPS) was carried out to further analyze the bonding characteristics as well as the composition of CoPS @C nanocomposite (Fig. 3). The full XPS spectrum indicates that $\mathrm{Co}, \mathrm{P}, \mathrm{S}, \mathrm{C}$ and $\mathrm{O}$ elements exist in the CoPS@C nanocomposite, as shown in Fig. S1. $\dagger$ Fig. 3a displays the XPS spectrum of Co 2p. The peaks located at 779.3 and $794.2 \mathrm{eV}$ were attributed to the $2 \mathrm{p}_{3 / 2}$ and $2 \mathrm{p}_{1 / 2}$ of $\mathrm{Co}^{3+}$, respectively. ${ }^{50-52}$ Another doublet at 779.8 and $799.6 \mathrm{eV}$ was ascribed to $2 \mathrm{p}_{3 / 2}$ and $2 \mathrm{p}_{1 / 2}$ of $\mathrm{Co}^{2+}$, while the other two peaks at 782.4 and $803.6 \mathrm{eV}$ were satellites. ${ }^{53-57}$ The $2 \mathrm{p}_{3 / 2}$ and $2 \mathrm{p}_{1 / 2}$ peaks of $\mathrm{P} 2 \mathrm{p}$ core level spectrum located at 129.3 and $130.1 \mathrm{eV}$, respectively as displayed in Fig. 3b, while the peak at $134.2 \mathrm{eV}$ was attributed to the $\mathrm{P}-\mathrm{O}$ bond due to the surface oxidation..$^{58-62}$ The spectra of $\mathrm{S}$ $2 p$ are shown in Fig. 3c. Two peaks at 162.4 and $163.7 \mathrm{eV}$ were attributed to $\mathrm{S} 2 \mathrm{p}_{3 / 2}$, while the peaks at 165.1 and $168.7 \mathrm{eV}$ represent the spin-orbit contributions from $S 2 \mathrm{p}_{1 / 2} \cdot{ }^{63-69} \mathrm{~A}$ very strong signal at $284.7 \mathrm{eV}$ corresponds to the $\mathrm{C} 1 \mathrm{~s}$ peak of CoPS@C sample, as shown in Fig. 3d. ${ }^{70}$
The test for OER performance was performed in $1 \mathrm{M} \mathrm{KOH}$ using a standard three-electrode system at room temperature, and the electrocatalytic activity of $\mathrm{RuO}_{2}$ was also measured for comparison. As shown in Fig. 4a, the electrode of CoPS@C exhibits enhanced OER performance compared with the bulk CoPS electrode. The CoPS@C can generate a current density of $10 \mathrm{~mA} \mathrm{~cm}^{-2}$ at an overpotential of $313 \mathrm{mV} v s$. RHE, lower than that of the bulk CoPS (395 mV vs. RHE). We also cycled our CoPS@C catalyst continuously for 1000 cycles in $1 \mathrm{M} \mathrm{KOH}$ solution at a scan rate of $50 \mathrm{mV} \mathrm{s}^{-1}$, and $I-V$ curves were obtained before and after the cycling, as displayed in Fig. S2. $\dagger$ In addition, based on the LSV curves, the corresponding Tafel plots are constructed. The Tafel plot is a useful parameter to evaluate catalytic activity as well as an indicator of the reaction mechanism. ${ }^{71-73}$ Fig. 4b shows that the Tafel slope value of CoPS@C catalyst is about $90 \mathrm{mV} \mathrm{dec}{ }^{-1}$, much lower than those of bulk CoPS (141 $\left.\mathrm{mV} \mathrm{dec}^{-1}\right)$, which further confirms the faster reaction kinetics and superior electrocatalytic OER performance of CoPS@C. To provide further insight into the intrinsic catalytic property, the electrochemical active surface area (ECSA) of catalysts was also evaluated via the cyclic voltammetry (CV) method, which is proportional to the electrochemical doublelayer capacitance $\left(C_{\mathrm{dl}}\right)^{74-76}$ The $\mathrm{CV}$ testing of CoPS@C nanocomposite and bulk CoPS were carried out from 0.36 to $0.46 \mathrm{~V}$ at 

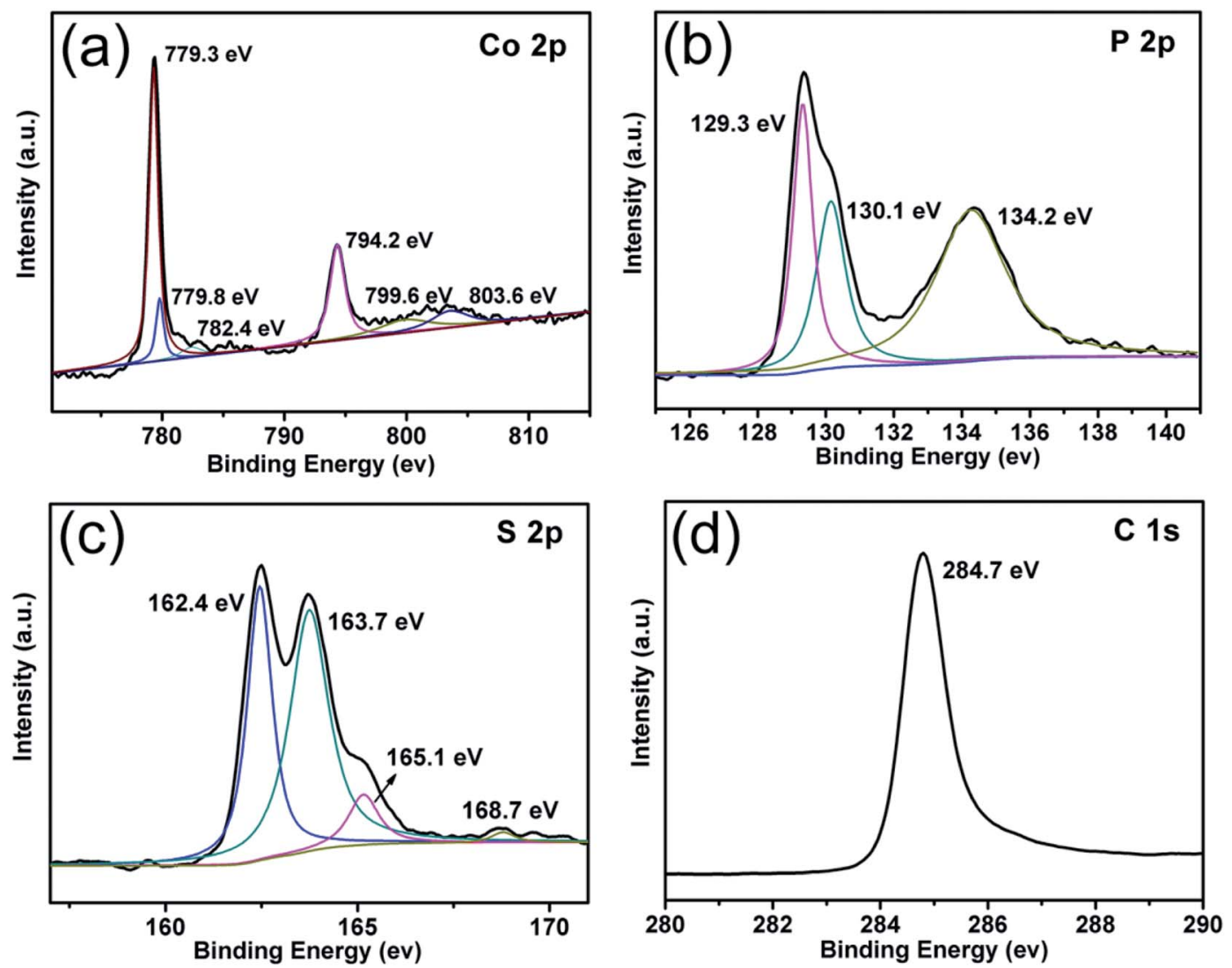

Fig. 3 X-ray photoelectron spectral regions for (a) Co $2 p$ (b) P $2 p$ (c) S $2 p$ and (d) $C$ 1s levels.

different scan rates (Fig. $4 \mathrm{c}$ and Fig. $\mathrm{S} 3 \dagger$ ), and the differences between anode and cathode current density at $0.41 \mathrm{~V}$ plotted against scan rate are fitted to gain the $C_{\mathrm{dl}}$. It was calculated that the $C_{\mathrm{dl}}$ of CoPS@C nanocomposite and bulk CoPS were 120.3 $\mathrm{mF} \mathrm{cm} \mathrm{cm}^{-2}$ and $44.7 \mathrm{mF} \mathrm{cm}^{-2}$ respectively, which demonstrated that CoPS@C nanocomposite can provide more active sites,
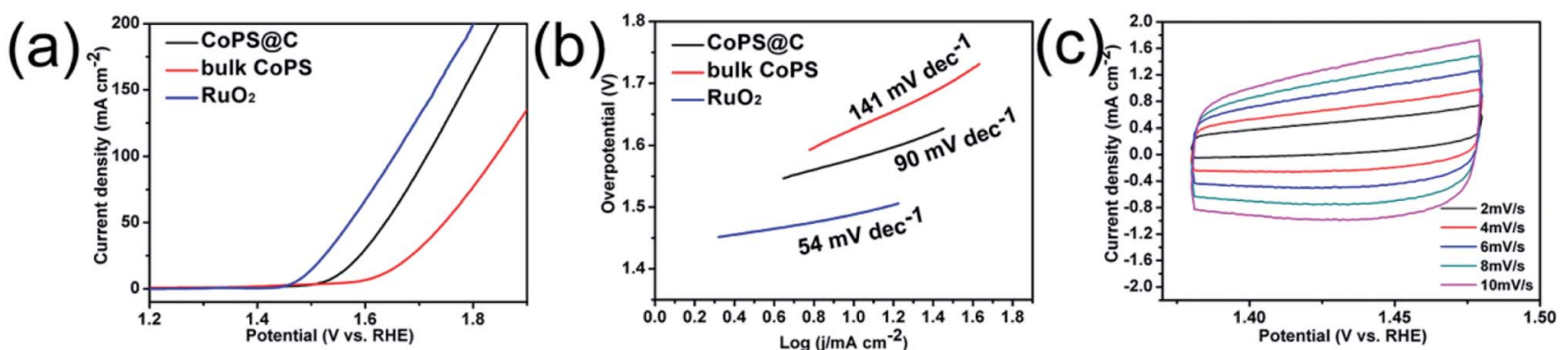

(d)
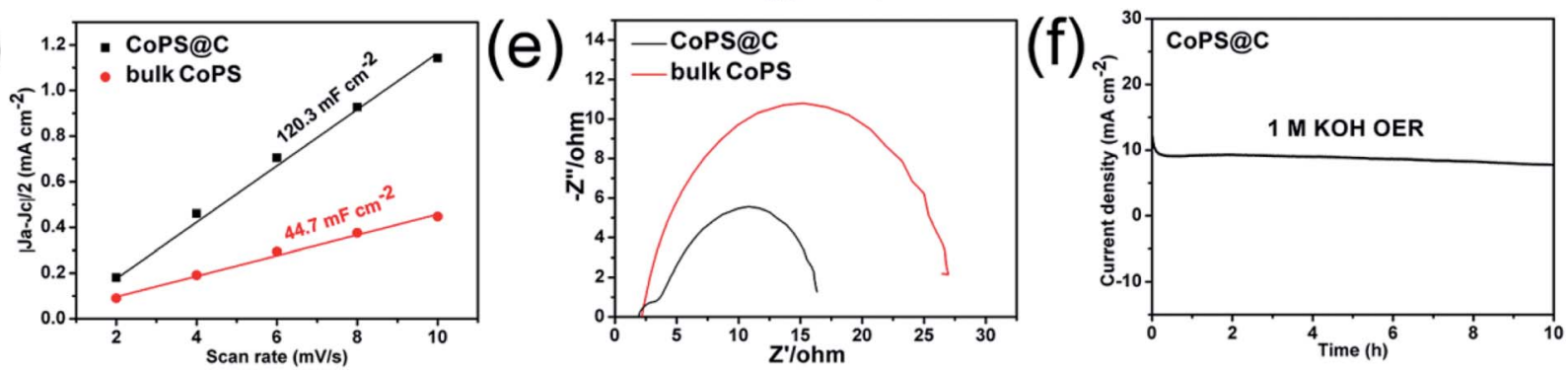

Fig. 4 (a) LSV curves of COPS@C, bulk CoPS and a commercial RuO 2 catalyst in $1 \mathrm{M} \mathrm{KOH}$ solution (scan rate $5 \mathrm{mV} \mathrm{s}^{-1}$ ) for the OER. (b) Tafel plots of the above catalysts for the OER in $1 \mathrm{M} \mathrm{KOH}$ solution. (c) Cyclic voltammograms of CoPS@C at different scan rates. (d) The plots show the extraction of the double-layer capacitance of CoPS (aC and bulk CoPS. (e) Electrochemical impedance spectra (EIS) Nyquist plots of CoPS (aC and bulk CoPS. (f) Time-dependent current density curve of CoPS@C for OER in $1 \mathrm{M} \mathrm{KOH}$ solution. 
(a)

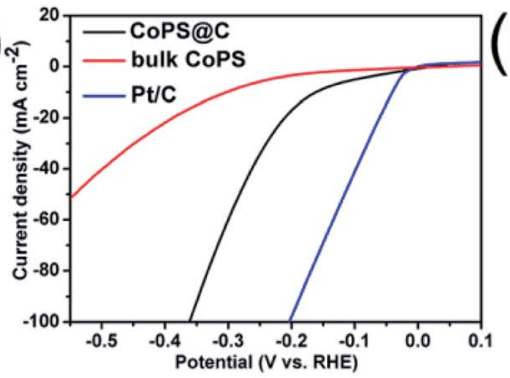

(b)

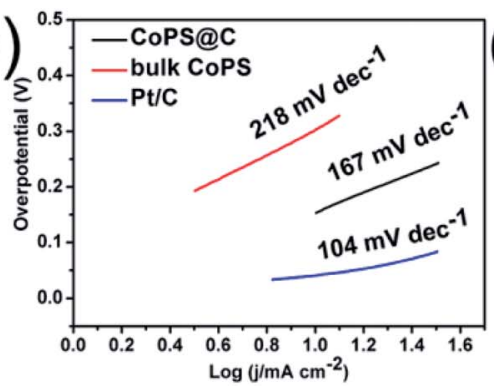

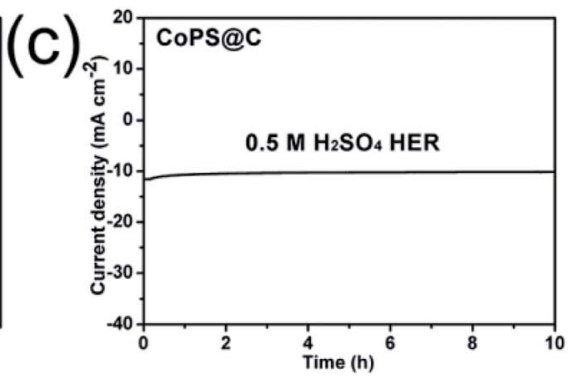

Fig. 5 (a) LSV curves of CoPS aC, bulk CoPS and a commercial Pt/C catalyst (scan rate $5 \mathrm{mV} \mathrm{s}^{-1}$ ) in $0.5 \mathrm{M} \mathrm{H}_{2} \mathrm{SO}_{4}$ solution for the HER. (b) Tafel plots of the above catalysts for the HER in $0.5 \mathrm{M} \mathrm{H}_{2} \mathrm{SO}_{4}$ solution. (c) Time-dependent current density curve of CoPS@C for HER in $0.5 \mathrm{M} \mathrm{H}_{2} \mathrm{SO}_{4}$ solution.

corresponding to excellent electrocatalytic activity, as shown in Fig. 4d. Furthermore, the electrochemical impedance spectroscopy (EIS) measurements were carried out for CoPS@C nanocomposite and bulk CoPS to investigate the kinetics of the electrode reaction, as shown in Fig. 4e. The semicircle observed in the Nyquist plots represents the charge transfer resistance $\left(R_{\mathrm{ct}}\right) \cdot{ }^{77-81}$ The smaller semicircle is observed for the CoPS@C nanocomposite, indicating the smaller $R_{\mathrm{ct}}$, and thus the faster
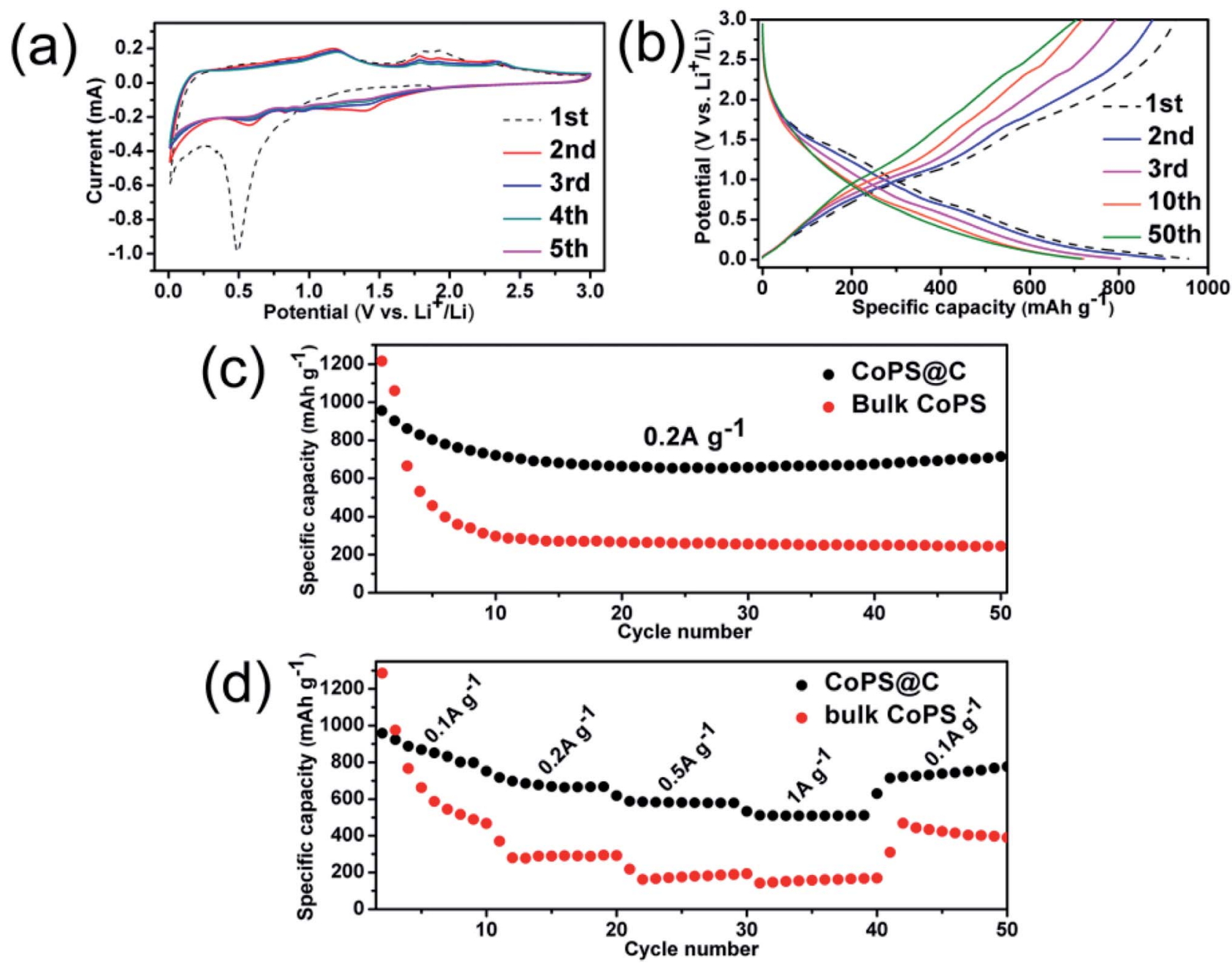

Fig. 6 (a) The first five voltammograms of the CoPS $\mathrm{CC}$ nanocomposite electrode in the voltage ranging from $0.01 \mathrm{~V}$ to $3 \mathrm{~V}$ at the scan speed of $0.1 \mathrm{mV} \mathrm{s}^{-1}$. (b) Galvanostatic charge-discharge curves of the CoPS@C nanocomposite electrode at a current density of $0.2 \mathrm{~A} \mathrm{~g}^{-1}$. (c) Cycling performance of CoPS@C and bulk CoPS electrodes at a current density of $0.2 \mathrm{~A} \mathrm{~g}^{-1}$. (d) Rate capability of CoPS@C and bulk CoPS electrodes at current densities ranging from $0.1 \mathrm{~A} \mathrm{~g}^{-1}$ to $1 \mathrm{~A} \mathrm{~g}^{-1}$. 
OER kinetics than bulk CoPS. Stability is another important performance characteristic for catalysts. Testing of the longterm durability of the CoPS@C nanocomposite for OER was performed by chronoamperometry measurement at $0.31 \mathrm{~V}$ for $10 \mathrm{~h}$ (Fig. 4f), and the decrease in the current density was almost negligible.

Besides, the HER performance of the electrode was tested in $0.5 \mathrm{M} \mathrm{H}_{2} \mathrm{SO}_{4}$ using a standard three-electrode system at room temperature. Fig. 5a shows linear sweep voltammetry (LSV) curves of the CoPS@C and bulk CoPs from $-0.6 \mathrm{~V}$ to $0.1 \mathrm{~V} v s$. RHE with a scan rate of $5 \mathrm{mV} \mathrm{s}^{-1}$. The commercial Pt/C catalyst (20 wt\%) was also examined for comparison. As expected, the $\mathrm{Pt} / \mathrm{C}$ shows excellent HER activity with a near-zero overpotential. The polarization curves of CoPS@C has a smaller overpotential (154 mV vs. RHE) than bulk CoPS (304 mV vs. RHE) to achieve a geometric current density of $-10 \mathrm{~mA} \mathrm{~cm}{ }^{-2}$. To evaluate the long durability of the electrode for HER activity, we cycled the electrode continuously for 1000 cycles in $0.5 \mathrm{M} \mathrm{H}_{2} \mathrm{SO}_{4}$ solution at a scan rate of $50 \mathrm{mV} \mathrm{s}^{-1}$, as displayed in Fig. S4. $\dagger$ As shown in Fig. 5b, the Tafel slope of CoPS@C is $167 \mathrm{mV} \mathrm{dec}^{-1}$, which is smaller than those of bulk CoPS $\left(218 \mathrm{mV} \mathrm{dec}^{-1}\right)$, suggesting the faster reaction kinetics and better HER efficiency of CoPS@C. The stability of CoPS for HER was tested at $-0.36 \mathrm{~V}$ for $10 \mathrm{~h}$ by Chronoamperometry. Fig. $5 \mathrm{c}$ shows that the decrease in the current density was almost negligible.

The electrochemical properties of the as-synthesized CoPS@C nanocomposite are further tested by CV (cyclic voltammetry) between 0.01 and $3.0 \mathrm{~V}$ (scan rate $0.1 \mathrm{mV} \mathrm{s}^{-1}$ ). Fig. 6a shows the first five consecutive CV of the CoPS@C electrode. During the cathodic sweep, there is an obvious reduction peaks consisted of two peaks centered at 1.41 and $0.56 \mathrm{~V}$, which can be attributed to the conversion reaction of $\mathrm{Li}$ with $\mathrm{CoPS}^{82-84}$ During the anodic sweep, oxidation peaks locate at 1.18, 1.78 and $2.34 \mathrm{~V}$ corresponded to lithium ion delithiation reaction. ${ }^{85-87}$ From the second cycle, the CV curves mostly overlap, indicating the good reversibility of the electrochemical reactions. Fig. $6 \mathrm{~b}$ shows the discharge and charge curves for the 1 st, 2nd, 3rd, 10th and 50th cycles at a current density of $0.2 \mathrm{~A} \mathrm{~g}^{-1}$. Consistent with the above CV results, a platform at $0.5 \mathrm{~V}$ is observed in the discharge process. Upon charge, a platform located at $1.75 \mathrm{~V}$ is observed. Fig. S5† shows the four voltammograms of CoPS@C nanocomposite electrode after 50 cycles at the current density of $0.2 \mathrm{~A} \mathrm{~g}^{-1}$ to verify the cycling stability. As expected, the observed peaks during the cathodic and anodic sweep were consistent with the result in Fig. 6a. To further investigate the lithium storage mechanism of CoPS@C electrode, ex situ XRD test on the discharged electrodes were performed. However, the signals from XRD pattern are too weak due to amorphous products, as displayed in Fig. S6. $\dagger$ Fig. 6c displays the representative cyclic performances of CoPS@C and bulk CoPS electrodes at a current density of $0.2 \mathrm{~A} \mathrm{~g}^{-1}$. The bulk CoPS electrode exhibits a capacity of about $245 \mathrm{~mA} \mathrm{~h} \mathrm{~g}^{-1}$ after 50 cycles. As for CoPS@C electrode, a reversible capacity of $713 \mathrm{~mA} \mathrm{~h} \mathrm{~g}^{-1}$ was retained over 50 cycles. Comparing with the bulk CoPS electrode, the CoPS@C electrode shows more excellent electrochemical performance. Fig. 6d depicts the rate capability of CoPS@C and bulk CoPS electrodes. The capacities of the CoPS@C electrode at current densities of $0.1 \mathrm{~A} \mathrm{~g}^{-1}$, $0.2 \mathrm{~A} \mathrm{~g}^{-1}, 0.5 \mathrm{~A} \mathrm{~g}^{-1}, 1.0 \mathrm{~A} \mathrm{~g}^{-1}$ and $0.1 \mathrm{~A} \mathrm{~g}^{-1}$ are around 816,668 , 581, 512 and $778 \mathrm{~mA} \mathrm{~h} \mathrm{~g}^{-1}$. As for bulk CoPS electrode, the capacities at $0.1 \mathrm{~A} \mathrm{~g}^{-1}, 0.2 \mathrm{~A} \mathrm{~g}^{-1}, 0.5 \mathrm{~A} \mathrm{~g}^{-1}, 1.0 \mathrm{~A} \mathrm{~g}^{-1}$ and $0.1 \mathrm{~A} \mathrm{~g}^{-1}$ are around 417, 292, 186, 171 and $398 \mathrm{~mA} \mathrm{~h} \mathrm{~g}{ }^{-1}$, respectively.

\section{Conclusions}

In summary, we have developed a facile synthetic route for the cellular CoPS@C nanocomposite. The performances of CoPS@C as a non-noble metal catalyst for HER in an acidic medium and OER in an alkaline medium show better activity than bulk CoPS sample. On the other hand, CoPS@C as a novel anode was found to be active in lithium ion batteries, exhibiting a high capacity $713 \mathrm{~mA} \mathrm{~h} \mathrm{~g}^{-1}$ at current density of $0.2 \mathrm{~A} \mathrm{~g}^{-1}$ and excellent reversibility over 50 cycles, indicating its potential applications in LIBs.

\section{Conflicts of interest}

The authors declare that they have no conflict of interest.

\section{Acknowledgements}

This work was supported by the National Natural Science Foundation of China (Grant No. 21671182).

\section{References}

1 J. P. Holdren, Science, 2008, 319, 424-434.

2 S. E. Habas, H. A. S. Platt, M. F. A. M. V. van Hest and D. S. Ginley, Chem. Rev., 2010, 110, 6571-6594.

3 T. R. Cook, D. K. Dogutan, S. Y. Reece, Y. Surendranath, T. S. Teets and D. G. Nocera, Chem. Rev., 2010, 110, 64746502.

4 B. W. Hao and W. L. Xiong, Sci. Adv., 2017, 3, 9252.

5 H. Yang, Y. Long, Y. Zhu, Z. Zhao, P. Ma, J. Jin and J. Ma, Green Chem., 2017, 19, 5809-5817.

6 C. G. Moralesguio, L. A. Stern and X. Hu, Chem. Soc. Rev., 2014, 43, 6555-6569.

7 C. Sun, Q. Dong, J. Yang, Z. Dai, J. Lin, P. Chen, W. Huang and X. Dong, Nano Res., 2016, 9, 2234-2243.

8 J. Greeley, T. F. Jaramillo, J. Bonde, I. B. Chorkendorff and J. K. Norskov, Nat. Mater., 2006, 5, 909-913.

9 Q. Liu, L. S. Xie, Z. Liu, G. Du, A. M. Asiri and X. P. A. Sun, Chem. Commun., 2017, 53, 12446-12449.

10 X. Q. Ji, B. P. Liu, X. Ren, X. F. Shi, A. M. Asiri and X. P. Sun, ACS Sustainable Chem. Eng., 2018, 6, 4499-4503.

11 F. Li, Y. Bu, Z. Lv, J. Mahmood, G. F. Han, I. Ahmad, G. Kim, Q. Zhong and J. B. Baek, Small, 2017, 13, 1701167.

12 F. Yang, Y. Chen, G. Cheng, S. Chen and W. Luo, ACS Catal., 2017, 7, 3824-3831.

13 H. T. Du, R. M. Kong, X. X. Guo, F. L. Qu and J. H. Li, Nanoscale, 2018, 10, 21617-21624.

14 C. Wu, Y. J. Yang, D. Dong, Y. H. Zhang and J. H. Li, Small, 2017, 13, 1602873. 
15 S. Li, G. Zhang, X. Tu and J. Li, ChemElectroChem, 2018, 5, 701-707.

16 M. Sun, H. Liu, J. Qu and J. Li, Adv. Energy Mater., 2016, 6, 1600087-1600121.

17 G. Zhang, G. C. Wang, Y. Liu, H. J. Liu, J. H. Qu and J. H. Li, J. Am. Chem. Soc., 2016, 138, 14686-14693.

18 P. Yu, L. Wang, Y. Xie, C. Tian, F. Sun, J. Ma, M. Tong, W. Zhou, J. Li and H. Fu, Small, 2018, 14, 1801717.

19 X. Zhang, S. Liu, Y. Zang, R. Liu, G. Liu, G. Wang, Y. Zhang, H. Zhang and H. Zhao, Nano Energy, 2016, 30, 93-102.

20 W. Xiao, P. Liu, J. Zhang, W. Song, Y. P. Feng, D. Gao and J. Ding, Adv. Energy Mater., 2017, 7, 1602086.

21 H. Huang, X. Feng, C. Du and W. Song, Chem. Commun., 2015, 51, 7903-7906.

22 J. Zhuo, M. Cabanacevedo, H. Liang, L. Samad, Q. Ding, Y. Fu, M. Li and S. Jin, ACS Catal., 2015, 5, 6355-6361.

23 M. Caban-Acevedo, M. L. Stone, J. R. Schmidt, J. G. Thomas, Q. Ding, H. C. Chang, M. L. Tsai, J. H. He and S. Jin, Nat. Mater., 2015, 14, 1245-1251.

24 T. Wu, M. L. Stone, M. J. Shearer, M. J. Stolt, I. A. Guzei, R. J. Hamers, R. F. Lu, K. M. Deng, S. Jin and J. R. Schmidt, ACS Catal., 2018, 8, 1143-1152.

25 Y. Hu, F. Li, Y. Long, H. Yang, L. Gao, X. Long, H. Hu, N. Xu, J. Jin and J. Ma, J. Mater. Chem. A, 2018, 6, 10433-10440.

26 B. Scrosati, J. Hassoun and Y. K. Sun, Energy Environ. Sci., 2011, 4, 3287-3295.

27 A. Manthiram, B. Song and W. Li, Energy Storage Materials, 2017, 6, 125-139.

28 Q. Xu, J. Y. Li, J. K. Sun, Y. X. Yin, L. J. Wan and Y. G. Guo, Adv. Energy Mater., 2017, 7, 1601481.

29 H. Zhang, X. Huang, O. Noonan, L. Zhou and C. Yu, Adv. Funct. Mater., 2017, 27, 1606023.

30 X. Zuo, J. Zhu, P. Müller-Buschbaum and Y. J. Cheng, Nano Energy, 2017, 31, 113.

31 K. Huo, L. Wang, C. Peng, X. Peng, Y. Li, Q. Li, Z. Jin and P. K. Chu, J. Mater. Chem., 2016, 4, 7585-7590.

32 M. M. Rahman, I. Sultana, T. Yang, Z. Chen, N. Sharma, A. M. Glushenkov and Y. Chen, Angew. Chem., Int. Ed., 2016, 55, 16059.

33 W. Li, H. Li, Z. Lu, L. Gan, L. Ke, T. Zhai and H. Zhou, Energy Environ. Sci., 2015, 8, 3629.

34 C. Kim, G. Hwang, J. W. Jung, S. H. Cho, J. Y. Cheong, S. Shin, S. Park and I. D. Kim, Adv. Funct. Mater., 2017, 27, 1605975.

35 J. Yang, Y. Zhang, C. C. Sun, H. Z Liu, L. Q. Li, W. L. Si, W. Huang, Y. Yan and X. C. Dong, Nano Res., 2016, 9, 612621.

36 Z. S. Zhang, J. Yang, Y. Nuli, B. F. Wang and J. Q. Xu, Solid State Ionics, 2005, 176, 693.

37 Y. Cui, M. Xue, Z. Fu, X. Wang and X. Liu, J. Alloys Compd., 2013, 555, 283-290.

38 S. Kong, Z. Jin, H. Liu and Y. Wang, J. Phys. Chem. C, 2014, 118, 25355-25364.

39 Y. Gu, Y. Xu and Y. Wang, ACS Appl. Mater. Interfaces, 2013, 5, 801-806.
40 Y. Chen, X. Li, K. Park, L. Zhou, H. Huang, Y. W. Mai and J. B. Goodenough, Angew. Chem., Int. Ed., 2016, 55, 1583115834.

41 F. Han, C. Zhang, B. Sun, W. Tang, J. Yang and X. Li, Carbon, 2017, 118, 731-742.

42 J. Jiang, C. Wang, J. Zhang, W. Wang, X. Zhou, B. Pan, K. Tang, J. Zuo and Q. Yang, J. Mater. Chem. A, 2015, 3, 499-503.

43 J. Zhou, H. Song, X. Chen, L. Zhi, S. Yang, J. Huo and W. Yang, Chem. Mater., 2009, 21, 2935.

44 L. Si, Z. Yuan, J. Liang, L. Hu, Y. Zhu and Y. Qian, J. Mater. Chem. A, 2014, 2, 9784.

45 H. Li, X. Huang, L. Chen, Z. Wu and Y. Liang, Electrochem. Solid-State Lett., 1999, 2, 547.

46 S. C. Lyu, B. C. Liu, C. J. Lee, H. K. Kang, C. W. Yang and C. Y. Park, Chem. Mater., 2003, 15, 3951-3954.

47 J. T. Han, Y. H. Huang and J. B. Goodenough, Chem. Mater., 2011, 23, 2027.

48 J. S. Chen and X. W. Lou, Small, 2013, 9, 1877.

49 X. W. Lou, J. S. Chen, P. Chen and L. A. Archer, Chem. Mater., 2009, 21, 2868.

50 Y. Pan, K. Sun, S. Liu, X. Cao, K. Wu, W. C. Cheong, Z. Chen, Y. Wang, Y. Li, Y. Liu, D. Wang, Q. Peng, C. Chen and Y. Li, J. Am. Chem. Soc., 2018, 140, 2610-2618.

51 B. C. Qiu, L. J. Cai, Y. Wang, Z. Y. Lin, Y. P. Zuo, M. Y. Wang and Y. Chai, Adv. Funct. Mater., 2018, 28, 1706008.

52 Z. Wang, Y. Lu, Y. Yan, T. Y. P. Larissa, X. Zhang, D. Wuu, H. Zhang, Y. Yang and X. Wang, Nano Energy, 2016, 30, 368-378.

53 Y. Su, Y. Zhu, H. Jiang, J. Shen, X. Yang, W. Zou, J. Chen and C. Li, Nanoscale, 2014, 6, 15080.

54 M. Ibrahim, C. Marcelotgarcia, K. A. Atmane, E. Berrichi, L. M. Lacroix, A. Zwick, B. Warotfonrose, S. Lachaize, P. Decorse and J. Y. Piquemal, J. Phys. Chem. C, 2013, 117, 15808.

55 T. J. Chuang, C. R. Brundle and D. W. Rice, Surf. Sci., 1976, 59, 413-429.

56 J. Wang, Q. Yang, Z. Zhang and S. Sun, Chem. -Eur. J., 2010, 16, 7916-7924.

57 H. vanderHeide, R. Hemmel, C. F. vanBruggen and C. Haas, J. Solid State Chem., 1980, 33, 17-25.

58 X. Q. Ji, R. Zhang, X. F. Shi, A. M. Asiri, B. Z. Zheng and X. P. Sun, Nanoscale, 2018, 10, 7941-7945.

59 J. Zhang, R. J. Cui, X. A. Li, X. H. Liu and W. Huang, J. Mater. Chem. A, 2017, 5, 23536-23542.

60 T. Liu, L. Xie, J. Yang, R. Kong, G. Du, A. M. Asiri, X. Sun and L. Chen, ChemElectroChem, 2017, 4, 1840-1845.

61 H. Lei, M. Chen, Z. Liang, C. Liu, W. Zhang and R. Cao, Catal. Sci. Technol., 2018, 8, 2289-2293.

62 S. Li, G. Zhang, X. Tu and J. Li, ChemElectroChem, 2018, 5, 701-707.

63 K. Zhang, T. Zhang, J. Liang, Y. Zhu, N. Lin and Y. Qian, RSC Adv., 2015, 5, 14828-14831.

64 D. Brion, Appl. Surf. Sci., 1980, 5, 133.

65 X. F. Wang, Q. Y. Xiang, B. Liu, L. J. Wang, T. Luo, D. Chen and G. Z. Shen, Sci. Rep., 2013, 3, 2007. 
66 S. Suzuki, T. Kosaka, M. Saito, Y. Waseda, E. Matsubara and M. Oku, Scr. Mater., 1997, 36, 841.

67 N. K. Unsworth, I. Hancox, C. Argent Dearden, P. Sullivan, M. Walker, R. S. Lilley, J. Sharp and T. S. Jones, Org. Electron., 2014, 15, 2624.

68 J. Noh, E. Ito, K. Nakajima, J. Kim, H. Lee and M. Hara, J. Phys. Chem. B, 2002, 106, 7139.

69 M. Wang and K. B. Tang, Dalton Trans., 2019, 48, 3819-3824.

70 H. M. Liao, R. N. S. Sodhi and T. W. Coyle, J. Vac. Sci. Technol., A, 1993, 11, 2681.

71 Y. Li, H. Wang, L. Xie, Y. Liang, G. Hong and H. Dai, J. Am. Chem. Soc., 2011, 133, 7296-7299.

72 Q. Ding, B. Song, P. Xu and S. Jin, Chem, 2016, 1, 699-726.

73 Y. Li, S. Niu, D. Rakov, Y. Wang, M. Caban-Acevedo, S. Zheng, B. Song and P. Xu, Nanoscale, 2018, 10, 7291-7297.

74 X. Li, Y. Fang, X. Lin, M. Tian, X. An, Y. Fu, R. Li, J. Jin and J. Ma, J. Mater. Chem. A, 2015, 3, 17392.

75 J. Chang, Y. Ouyang, J. Ge, J. Wang, C. Liu and W. Xing, J. Mater. Chem. A, 2018, 6, 12353-12360.

76 C. C. L. McCrory, S. Jung, J. C. Peters and T. F. Jaramillo, J. Am. Chem. Soc., 2013, 135, 16977-16987.

77 C. Tang, R. Zhang, W. Lu, Z. Wang, D. Liu, S. Hao, G. Du, A. M. Asiri and X. Sun, Angew. Chem., 2017, 129, 860-864.
78 B. Losiewicz, A. Budniok, E. Rowinski, E. Lagiewka and A. Lasia, Int. J. Hydrogen Energy, 2004, 29, 145-157.

79 A. R. J. Kucernak and V. N. Naranammalpuram Sundaram, J. Mater. Chem. A, 2014, 2, 17435-17445.

80 P. Jiang, J. Chen, C. Wang, K. Yang, S. Gong, S. Liu, Z. Lin, M. Li, G. Xia, Y. Yang, J. Su and Q. Chen, Adv. Mater., 2018, 30, 1705324.

81 P. Jiang, Y. Yang, R. Shi, G. Xia, J. Chen, J. Su and Q. Chen, J. Mater. Chem. A, 2017, 5, 5475-5485.

82 Y. Kim and J. B. Goodenough, J. Phys. Chem. C, 2008, 112, 15060-15064.

83 Q. Wang, L. Jiao, Y. Han, H. Du, W. Peng, Q. Huan, D. Song, Y. Si, Y. Wang and H. Yuan, J. Phys. Chem. C, 2011, 115, 8300-8304.

84 X. Li, J. Liang, Y. Lu, Z. Hou, Q. Cheng, Y. Zhu and Y. Qian, Angew. Chem., Int. Ed., 2017, 56, 2937-2941.

85 Q. Liang, Y. Zheng, C. Du, Y. Luo, J. Zhang, B. Li, Y. Zong and Q. Yan, Small Methods, 2017, 1700304, DOI: 10.1002/ smtd.201700304.

86 Z. Gao, N. Song, Y. Zhang and X. Li, Nano Lett., 2015, 15, 8194-8203.

87 Z. Yu, J. Song, M. L. Gordin, R. Yi, D. Tang and D. Wang, Adv. Sci., 2015, 2, 1400020. 